\title{
A methodological approach to evaluating the sustainability level of a transport service
}

\author{
R. Rossi, M. Gastaldi \& R. Vescovi \\ Department of Structural and Transportation Engineering, \\ University of Padua, Italy
}

\begin{abstract}
Starting from the three-dimensional definition of the concept of sustainability (social, economic and environmental perspectives), this paper proposes a methodological approach based on the theory of fuzzy systems and the theory of possibility, such as will allow the determination of a single overall indicator for the sustainability of possible action plans on transport and territory. The methodology can be used to formalize the conceptual schema of the three dimensions of sustainable development widely referred to in literature as the "three pillars of sustainability". The method works on three different levels. At the first level, three fuzzy inference systems produce three sustainability indicators (social, economic and environmental), each using respective input variables (indicators commonly used for evaluation processes in the field of transportation systems analysis), and respective inference rules formulated by experts. At the second level, the fuzzy variables representing social, economic and environmental sustainability of the action become inputs for three different inference systems (based on rules formulated by experts), the outputs of the inference systems are indicators of equity (social/economic dimension), viability (economic/environmental dimension) and bearableness (social/environmental dimension). At the third level, the fuzzy variables produced from the previous level become input variables for an inference system, again based on set rules, which can be used to compose the different dimensions (social, economic and environmental) and deliver, as the final output, a fuzzy indicator of the durability and sustainability offered by the action plan.
\end{abstract}

Keywords: sustainability, fuzzy, evaluation. 


\section{Introduction}

This section is dedicated to a critical analysis of sustainability, in an attempt to summarize the different interpretations found in literature; the analysis serves to introduce the main part of the paper in which the authors present a methodological approach, based on the theory of fuzzy logic, for evaluating the level of sustainability offered by transport and land-use plans.

The concept of sustainable mobility has been widely debated in recent years, given its close links, self-evidently, with that of sustainable development. In effect, it is the concept of sustainable development that can give significance to the concept of sustainable mobility. There has been a trend latterly for associating various adjectives with the term 'development' - which appears to be inseparable from economic growth - as a response to the criticisms levelled at the concept. Thus far, the response has been unconvincing. In particular, contrasting positions are taken on 'sustainability':

- one school of thought champions the concept of sustainable development, whilst adopting different positions: there are those who maintain that development/growth, as we know it, can continue indefinitely (manufacturers, a number of politicians, and almost all economists); for others, development is conceptually social, human, local, etc.;

- another school (Latouche, [6]) rejects the concept of sustainable growth (indeed of growth itself), embracing decroissance - a retreat from growth, or 'degrowth'; this however is very much a minority persuasion as of now, with no control over the instruments of power linked to growth (markets, technological development, etc.), and aspires to a scenario that appears in conflict with reality.

In effect, this is a problem involving many variables combining to characterize the geosphere and new technologies, in other words, a 'system' of enormous complexity, susceptible to changes that are extremely difficult to forecast over time, and always opinionable. In this situation one can either analyze single factors, within limits, or describe the system as a whole in somewhat vague and in part abstract language; this is due to the indeterminate nature of sustainable development as a concept (for some, the concept is even an antinomy). Faced with a confusing and contradictory picture such as this, and considering the powerful influence of certain countries that appear to have embraced growth as a collective aspiration in their national psyche (with little concern for 'sustainability'), any notion of reversing the trend in the current climate would seem to be utopian.

In the case of transport, especially, it is plain to see how mobility conditions the present model of development, and of life in general. For example, accepting the globalization of markets as an inevitable fact of life (the position taken by a large majority of politicians and economic producers) would seem to be totally at odds with sustainability, and besides, is often the outcome of imbalances created by the trend toward a general transformation of the world - in economic terms based on the western model. 
For some years now, Italian governments have apparently espoused the concept of sustainable development, not least in the area of mobility, setting a number of basic targets aimed at reducing the environmental impact of transport systems. In this respect, certain general objectives have been set that would certainly appear creditable, namely: reducing pollutant emissions and reducing the need for mobility, increasing the availability of public transport, limiting the use of private motor transport, and implementing statutory measures to re-establish the land-use and modal balance of transport systems.

The alternative - undoubtedly more effective - would be to bring about a paradigmatic transformation involving the entire planet, or at least the most industrialized countries, although this would also necessitate a willingness for change not easy to bring about.

Measures consistent with courses of action inspired by concepts of sustainable development and mobility appear practicable at the present time and acceptable to a large body of public opinion, backed by the conviction that more radical changes in terms of sustainability can be achieved before the situation progresses beyond the 'point of no return' (difficult to forecast), mainly with regard to the environment. Set in the scenario outlined above, the study presented in this paper seeks to influence the thinking prevalent in these sectors, in line with certain of the objectives mentioned, as well as to inform the collective consciousness and the figures that play a large part in shaping that consciousness.

In particular, the paper proposes a methodological approach to evaluating the level of sustainability of a transport service. The method is to be applied as part of a general evaluation of alternative transport services in a municipality of the Province of Venice, and the results will appear in a further paper.

\section{Methodological approach}

Speaking of sustainability and its many definitions, it will be appropriate here to recall the general concept of sustainable development quoted by the TRB in 1997 which, adopting and expanding the definition given by the WCED in 1987, namely "development that meets the needs of the present without compromising the ability of future generations to meet their own needs", introduces a three dimensional vision of sustainability, starting from the premise that "environmental, economic, and social systems interact to their mutual advantage or disadvantage at various space-based scales of operation". From this perspective, a sustainable transport system is one that allows "the movement of people and goods by modalities that are sustainable from an environmental, economic and social point of view" (OECD [9] and Rassafi and Vaziri [10]). This three-dimensional vision finds expression in the conceptual schema that has entered literature and become known as the "three pillars of sustainability" (Fig.1): where development is bearable (socially and environmentally), equitable (socially and economically) and viable (environmentally and economically) it becomes sustainable/durable. 


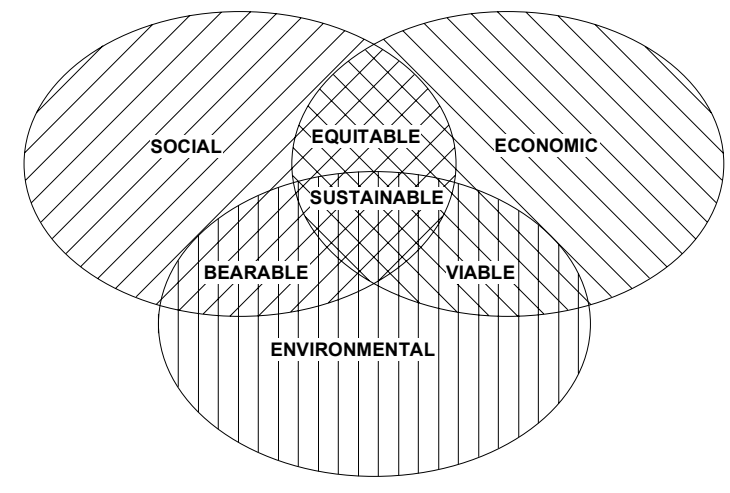

Figure 1: Components making up the definition of sustainable development.

The present paper sets forth a method which, in application, leads to the definition of a summary indicator that can be used to evaluate the sustainability of a given action plan for transportation and territorial systems. More exactly, and with reference to the findings of studies conducted in other areas, reported in literature (Andriantiatsaholiniauna et al. [1]; Yannis and Andriantiatsaholiniauna [14]; Dunn et al. [3]), this paper presents a formalization of the threedimensional concept of sustainability (fig. 1) based on the theory of fuzzy systems.

\subsection{Representation of sustainability indicators using fuzzy sets}

Processes for evaluating actions plans for territory/transportation system are based normally on a cost-benefit analysis, or on multi-criteria analyses. There is indeed an extensive bibliography on the subject, not confined solely to transportrelated measures. Looking specifically at the problem of evaluating the sustainability of a given action plan, an analysis of existing literature highlights three essential shortcomings in the evaluation methods normally adopted (Dunn et al. [3]):

1. the presence of non-homogeneous variables/quantities: variables/indicators involved in the evaluation of alternatives are measured on scales often of dissimilar nature (e.g.: monetary, physical, semantic, etc.);

2. information on the system (present and future) is characteristically uncertain and imprecise;

3. interrelation between the dimensions of sustainability: variables/indicators involved in the evaluation are often not univocally identifiable with one of the three dimensions (in terms of impact) but tend to permeate them, inducing 'overlaps'.

In general terms, planning implemented on systems will produce effects/impacts that must be identified and measured; indicated below are some examples of these impacts, classified on the basis of the pertinent dimension (Litman [7]): 
Environmental impacts

- gas emissions

- climate changes

- noise pollution

- hydrogeological impacts

- ecological/environmental degradation

- consumption of non-renewable resources

Economic impacts

- accessibility

- congestion

- infrastructure costs

- consumer costs

- accidents

- consumption of non-renewable resources

- $\ldots$...

Social impacts

- equity

- mobility of disadvantaged categories

- human health

- social cohesion

- quality of life

- ...

The method proposed requires the identification of indicators that will measure the extent to which the stated objectives are achieved (measurement of impacts, as compared to objectives), in terms of economic, social and environmental sustainability.

These indicators can be defined in relative terms, that is to say understood as variations in the parameters of interest associated with alternative action plans, relative to the status quo. Certain of these indicators are shown overleaf (table 1); naturally, the description of the method does not exclude the possibility of introducing other indicators in addition, or as alternatives, to those presented.

As certain of these indicators are routinely employed in evaluation processes, there will be no discussion here of their specific significance, in the interest of brevity, other than to mention how they can be represented in fuzzy variable domains.

In particular, it will be interesting to develop the analysis into the ways of determining and representing the indicator of social sustainability referred to here as the propensity of people to use "a transport service alternative to the existing service".

The improvement in quality of life of the user, connected with the introduction of a new transport service, can be measured indirectly by the propensity of the user to utilize the new service and drop the existing service. 
Table 1: Sustainability indicators that can be associated with a transport/territory action plan.

\begin{tabular}{|c|c|}
\hline type & description \\
\hline $\begin{array}{l}\text { indicators of } \\
\text { environmental } \\
\text { sustainability }\end{array}$ & 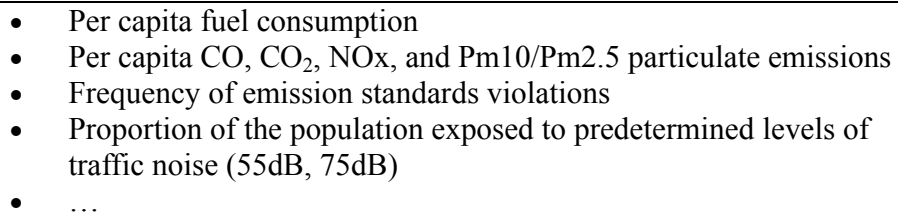 \\
\hline $\begin{array}{l}\text { indicators of } \\
\text { economic } \\
\text { sustainability }\end{array}$ & $\begin{array}{ll}\text { - } & \text { Average travel time on OD relations of interest } \\
\text { - } & \text { Number of workplaces and services located within X minutes } \\
\text { - } & \text { Per cavel time of residential areas } \\
\text { - } & \text { Per capita latenditure on automobile use and parking } \\
\text { - } & \text { Cost of road traffic accidents } \\
\text { - } & \text { Service and infrastructure costs (efficiency) } \\
\text { - } \quad \ldots .\end{array}$ \\
\hline $\begin{array}{l}\text { indicators of } \\
\text { social } \\
\text { sustainability }\end{array}$ & $\begin{array}{l}\text { - Propensity/satisfaction expressed by the user (with particular } \\
\text { reference to disadvantaged categories, disabled) in respect of } \\
\text { transport services proposed as alternative/complementary to } \\
\text { existing services (allowing measurement of the extent to which } \\
\text { the choice available to different groups of users has been } \\
\text { widened/improved, enhancing their quality of life) } \\
\text { - User satisfaction, especially among disadvantaged categories and } \\
\text { the disabled } \\
\text { - Contribution made by transport activities in delivering quality of } \\
\text { life objectives } \\
\text { - Proportion of household budget spent on transport by low income } \\
\text { families } \\
\text { - } \quad \text { Reduction of road traffic accidents } \\
\text {... }\end{array}$ \\
\hline
\end{tabular}

In the method proposed, the propensity in question is measured by using a questionnaire as part of an SP survey; this is a questionnaire (Rossi et al. [12]) in which the interviewee (potential user of the service) expresses a willingness, selected from a suitably constructed semantic scale of responses, to drop the transport service used currently (private car, motorcycle, bicycle, etc.) in view of the attraction presented by the hypothetical alternative service proposed.

The essential characteristic of the method is that, during analysis of the information gathered, it maintains the uncertainty (imperfect knowledge of the effects that would be produced by the alternatives on the various movements the user is obliged to complete within a given interval of time) associated with the semantic evaluations expressed by the subjects interviewed as regards their willingness to consider change; accordingly, the procedure is to adopt a mathematical structure consistent with the nature of the uncertainty, derived from the theory of possibility and of fuzzy sets (Klir and Yuan [4], Dubois and Prade [2]). The semantic scale (Rossi et al., [11] [12]) is translated formally into 


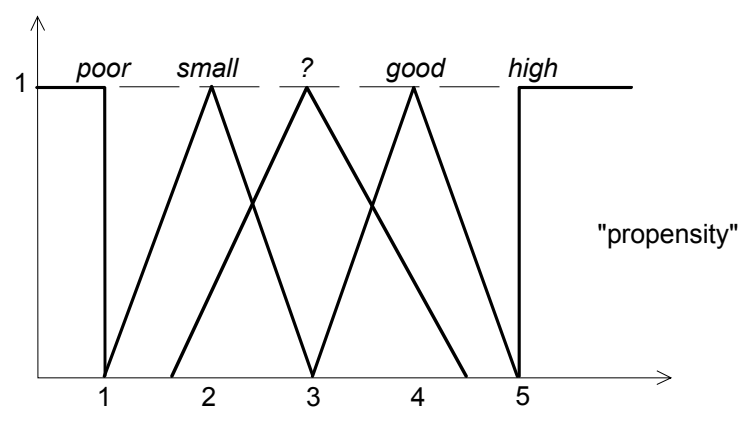

Figure 2: Example of a semantic scale for the expression of propensity to adopt transport services alternative to the service currently in use. The question mark '?' indicates an expression of inability on the part of the interviewee to make a judgement.

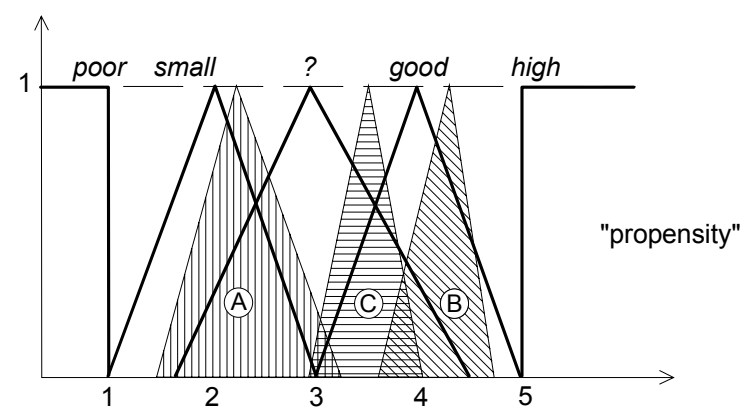

Figure 3: Propensity in respect of three transport services alternative to the service in use (A, B, C) represented by fuzzy intervals on the evaluation domain.

a set of fuzzy intervals, each of which representing one of the verbal evaluations indicative of an inclination to replace the current transport service with the hypothetical service offered in the survey (Fig.2).

Having recorded each of the propensities expressed by interviewees in respect of the generic hypothetical alternative, the next step is to determine an aggregate measurement of the response, relatable to the entire observation sample: this coincides with the average of the propensities taken as fuzzy intervals (Klir and Yuan, 1995). By way of example, Fig.3 shows the 'average' propensities associated with three alternatives (A, B, C) referred to the evaluation domain.

In addition to the specific case described above, the other sustainability indicators (Table 1) can be represented similarly by fuzzy sets on suitable domains; by way of example, the following figure illustrates two further types of indicators, and shows the corresponding formalizations in fuzzy terms. 


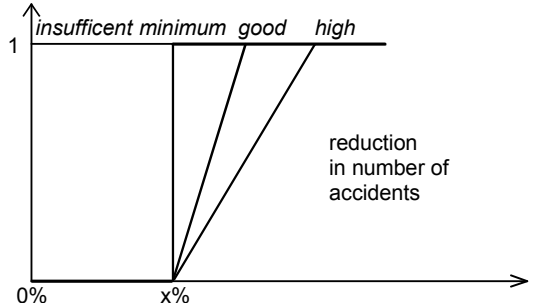

(a)

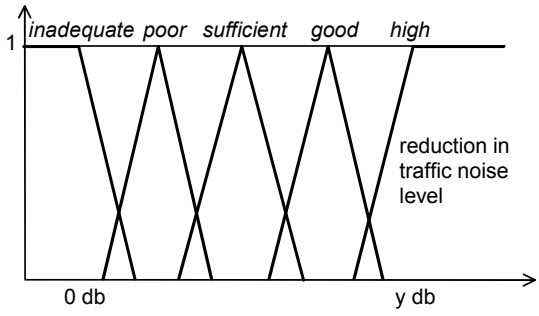

(b)

Figure 4: $\quad$ Method of representing certain sustainability indicators by means of fuzzy sets: (a) 'reduction in number of accidents'; (b) 'reduction in noise level'.

As regards road safety (Fig. 4(a)), a fuzzy variable can be constructed to interpret the concepts of a reduction in the number of traffic accidents 'insufficient', 'minimum', 'average' and 'high' - with the minimum being set as the variation relative to the status quo, corresponding to the percentage reduction set by competent agencies as the target to be achieved within a given time frame (e.g. a reduction of $20 \%$ in road traffic accidents by the year 2010).

In cases where no minimum variation thresholds have been defined for the indicator, it will be possible nonetheless to define a domain of the possible variations and a suitable semantic scale to qualify them (Fig. 4(b)).

\subsection{Architecture of the evaluation system}

The method proposed in this paper operates on three different levels making up the evaluation system (Fig. 5), interpreting the three-dimensional vision of the concept of sustainability (Fig.1), which is presented in Fig. 6 as an exploded diagram.

At the first level, a set of three fuzzy inference systems (FIS) outputs three corresponding sustainability indicators (Environmental, Economic and Social), each using respective input variables (indicators) and inference rules suitably defined by experts in the field through a process of comparison that could be conducted, for example, by way of focus groups (Zammuner [15]).

The output fuzzy variable (Fig. 7) indicates the level of sustainability, referring to the different components (Environmental, Economic and Social), by way of a semantic scale composed of five levels, from 'unsustainable' to 'sustainable'.

The rules employed in each inference system (for each dimension) are conditional and categorical in nature - such as 'if ... then ...' which combine to express a multi-conditional, approximate reasoning. A simple example of these rules would be the expression: "IF the propensity is high AND the level of safety is high, THEN the new transport service has a good level of social sustainability"; a possible formalization of this is shown in Fig. 8, where the rule is applied employing Mamdani's method (Mamdani [8]). 


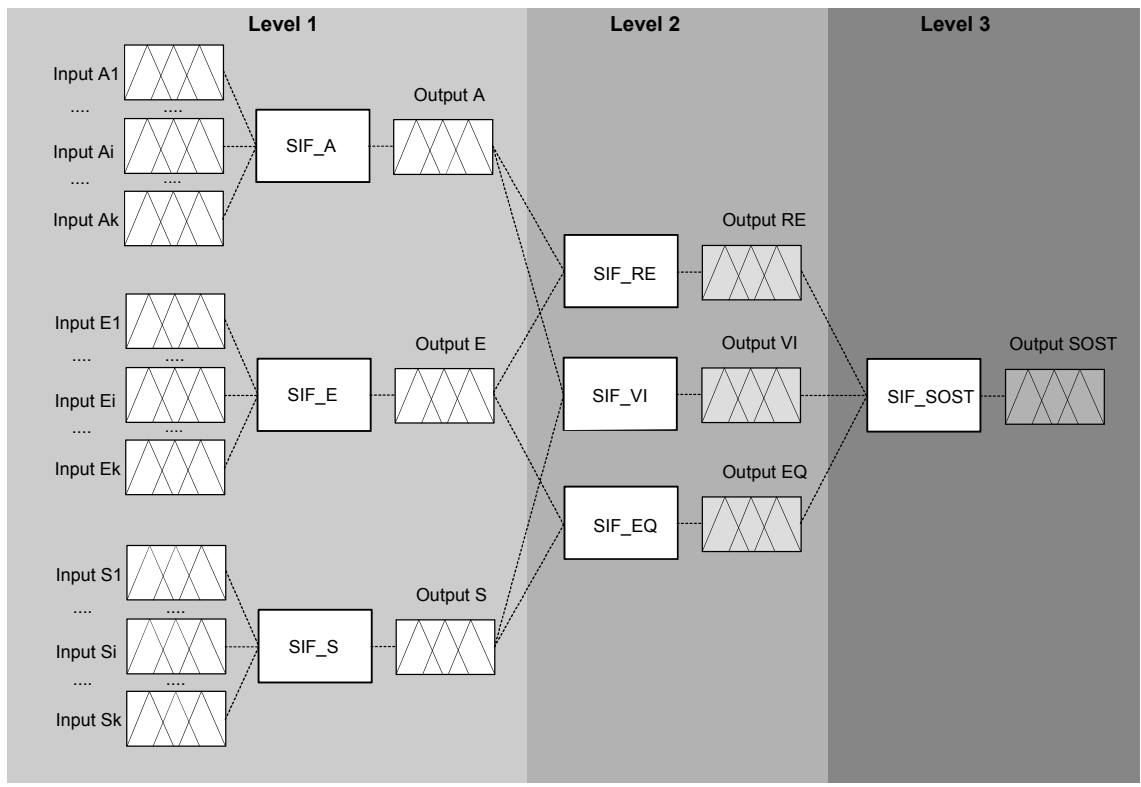

Figure 5: Schematic showing the three-level structure of the evaluation system.

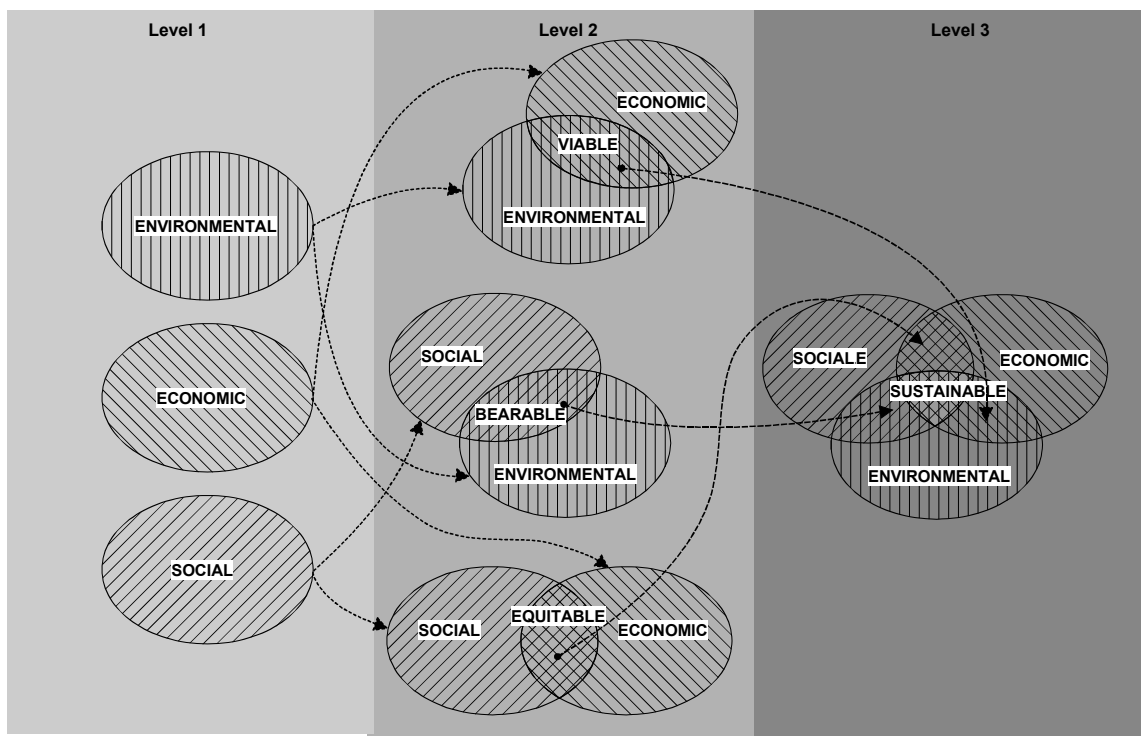

Figure 6: Exploded diagram showing the three-dimensional vision of the concept of sustainability. 


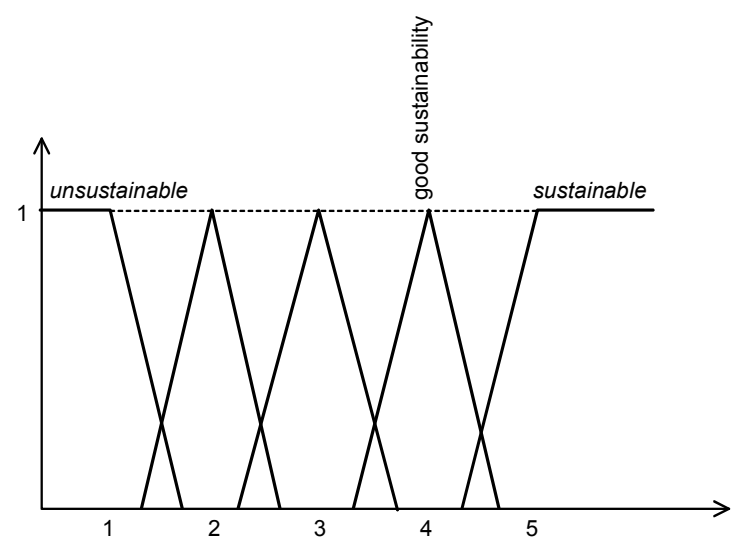

Figure 7: Level 1: output variable representing the level of sustainability (Environmental, Economic or Social).

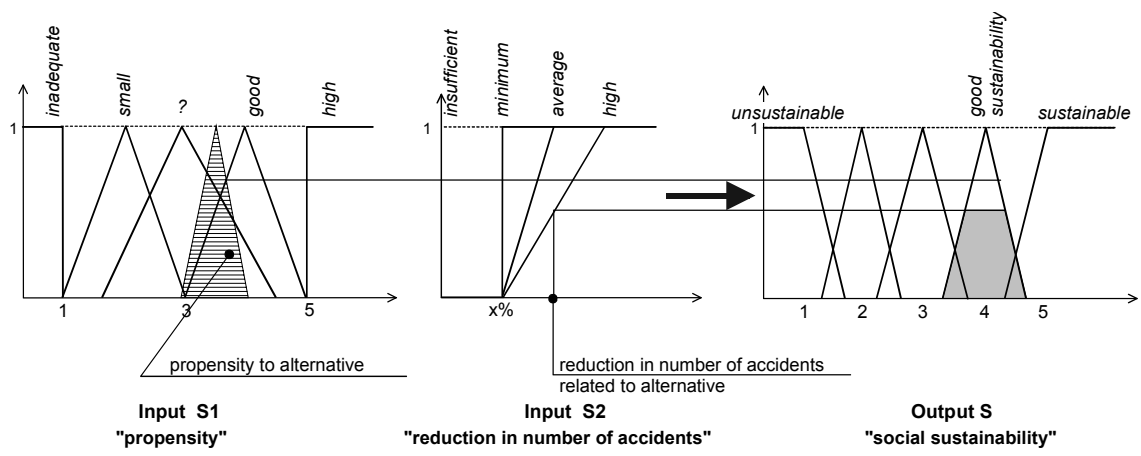

Figure 8: Level 1: application of a rule for evaluating the social sustainability of a transport service using Mamdani's method (Mamdani [8]).

The introduction of actual values for the input variables (values assumed from indicators for the specific alternative system) determines the activation of a certain number of rules belonging to the set of rules defined for the system; each of these produces a set of fuzzy outputs representing the level of sustainability in the three dimensions (Fig. 8).

All of the various fuzzy sets produced by activating the rules are consolidated thereafter into a single output fuzzy set, generally by joining the sets together ('joining' in the fuzzy sense of the term): this process is referred to conventionally as the aggregation of rules (Fig. 9).

In essence, the theory of fuzzy systems provides tools with which to formalize and assemble rules leading to the identification of a single fuzzy set (by applying appropriate inference methods, and after activating the rules on the basis of the assumed values of input variables) that will measure sustainability for each of the three dimensions - environmental, economic and social (outputs 


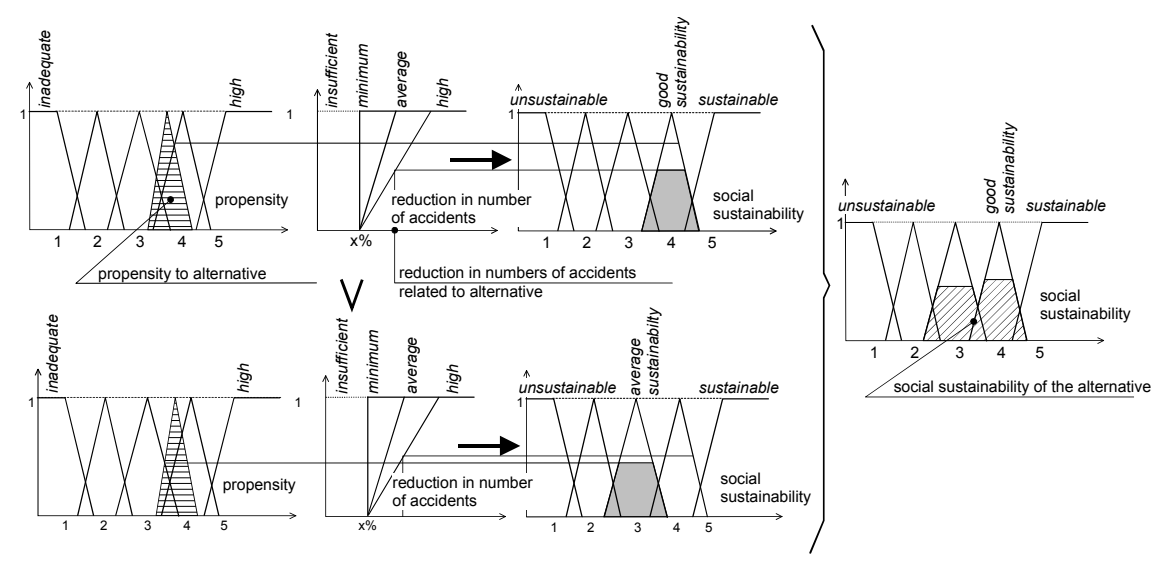

Figure 9: Level 1: example of the activation of two rules and their aggregation.

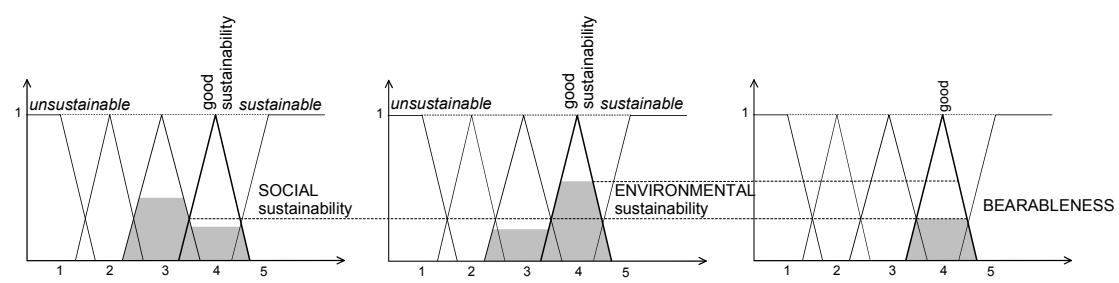

IF social sustainability is good AND environmental sustainability IS good THEN transportation service will produce good bearableness

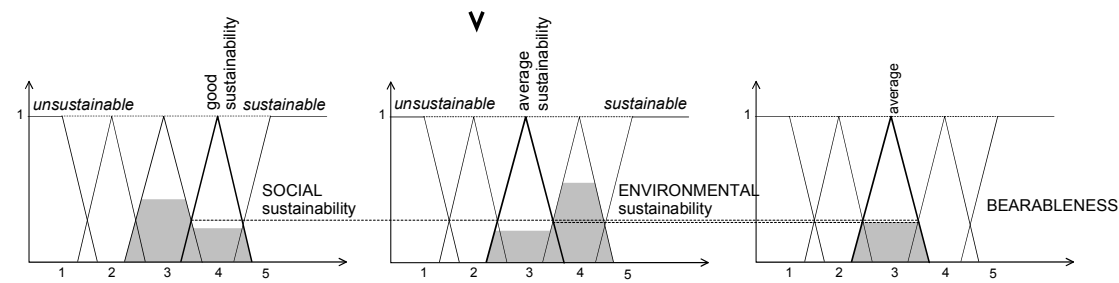

IF social sustainability is good AND environmental sustainability IS average THEN transportation service will produce average bearableness

two rules composition (union):

fuzzy set representation of alternative's bearableness

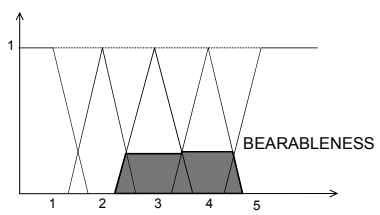

Figure 10: Level 2: example of the application of two rules. The inputs are fuzzy sets representing the social and environmental sustainability (outputs from level 1) of the alternative system under analysis; the output is a fuzzy measure of its 'bearableness'. 
A, E and S in the diagram of Fig. 5). These indicators of sustainability produced at level 1 become inputs for level 2 of the evaluation system.

At the second level, the fuzzy variables representing the social, environmental and economic sustainability of the action, considered in pairs, become inputs for three different inference systems (based on rules suitably defined by experts) of which the outputs are represented by fuzzy indicators of equity (social-economic dimension), viability (economic-environmental dimension) and bearableness (social-environmental dimension) (Fig. 5).

In this case the rules are categorical and conditional, involving two fuzzy variables at most for each inference system (there is no reason why there might not be rules involving one variable only, assuming a non-compensatory character); taken together, these rules provide the basis for multi-conditional approximate reasoning that can be formalized in the same way as seen already for fuzzy systems associated with level 1 of the evaluation system. The following illustration shows an example of two rules involving social and environmental sustainability (SIF_VI in Fig. 5).
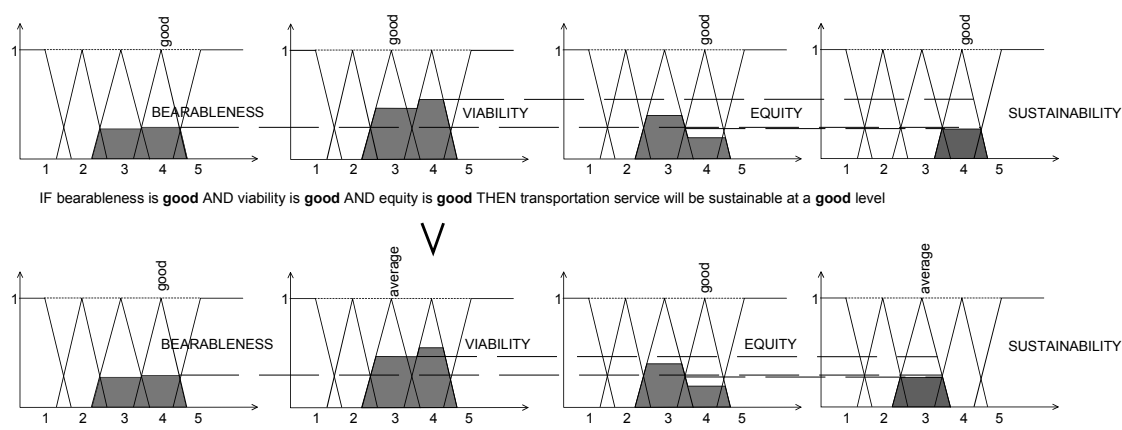

IF bearableness is good AND viability is average AND equity is good THEN transportation service will be sustainable at an average level

two rules composition (union):

fuzzy set of alternative's SUSTAINABILITY

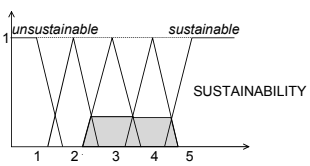

Figure 11: Level 3: example of the application of two rules. The inputs are fuzzy sets representing 'bearableness', 'viability' and 'equity (outputs from level 2) of the alternative under analysis; the output is a fuzzy measure of its 'sustainability' overall.

At the third and final level (Fig. 5, Fig. 6), the fuzzy variables obtained as outputs from the previous level become inputs for an inference system - again based on rules defined by experts - by way of which the different dimensions can be composed, producing an output that constitutes a fuzzy indicator of sustainability/durability (social-environmental-economic dimension). The rules involve, at most, the three fuzzy variables of bearableness, viability and equity (Fig. 11, for example, shows two rules involving the three input variables; these 
are activated by the corresponding values associated with the alternative under analysis, and their composition delivers the fuzzy set representing overall sustainability of the alternative). There is nothing, however, to exclude the possibility of applying rules relating only to pairs of such variables or even to single variables (non-compensatory rules).

At the end of the procedure, each alternative considered in the evaluation process will be represented by a fuzzy set indicative of the corresponding level of 'overall' sustainability, thereby supporting the decision-maker in selection of the alternative offering the best impact. In this regard, it seems sensible to adopt 'fuzzy ranking' techniques such as will give measurements of possibility/necessity regarding dominance between fuzzy sets defined on a given domain (Dubois and Prade [2]; Henn [5]; Rossi et al. [11] [12]), represented in this instance by the level of sustainability.

\section{Conclusions and future research}

The methodology proposed appears consistent with the three-dimensional schematization of the concept of sustainable/durable development established in literature. Using simplified mathematical tools derived from the theory of fuzzy systems, it allows the analyst to produce indicators of sustainability useful for evaluating transport services as alternatives to existing services in a given context, while maintaining the uncertainty (and ensuring the nature of uncertainty is respected) implicit in evaluation processes of this type.

The methodology is being experimented in the evaluation of various action plans proposed for qualitatively upgrading/improving the transport service of a municipality in the Province of Venice. This experimental phase, accompanied by a comparative analysis involving other methods of evaluation established in literature, will allow the authors to discover any elements of strength and weakness in the proposed method, so that it can continue to be developed effectively. The results of these studies will provide the subject matter for a further paper.

\section{Summary}

Starting from the three-dimensional definition of the concept of sustainability (environmental, economic and social perspectives), the present paper proposes a methodological approach based on the theory of fuzzy systems and the theory of possibility, aimed at determining a single indicator of sustainability for action plans applicable to transport and territory system: the methodology in question can be used to interpret and formalize the concept described in literature for representing the three dimensions of sustainable development, known as the 'three pillars of sustainability'.

The method operates on three different levels:

- at the first, a set of three fuzzy inference systems produces three sustainability indicators (social, environmental and economic), each using respective input variables (indicators used conventionally in processes for 
evaluating the sustainability of measures applied to the transport system), and respective inference rules suitably defined by experts in the field;

- at the second level, the fuzzy variables representing the social, environmental and economic sustainability of the action become inputs for three different inference systems (based on rules defined by experts) of which the outputs are represented by fuzzy indicators of equity (socialeconomic dimension), viability (economic-environmental dimension) and bearableness (social-environmental dimension);

- at the third and final level, the fuzzy variables obtained as outputs from the previous level become inputs for an inference system - again based on rules defined by experts - enabling the analyst to compose the different dimensions, producing an output that constitutes a fuzzy indicator of sustainability/durability (social-environmental-economic dimension).

The methodology is being experimented in the evaluation of alternative transport services for a municipality in the Province of Venice.

\section{References}

[1] Andriantiatsaholiniauna L. A., Vassilis S. K. and Yannis A. P., "Evaluating strategies for sustainable development: fuzzy logic reasoning and sensitivity analysis", Ecological Economics, 48: 149-172, (2004).

[2] Dubois D. and Prade H., Possibility Theory. An Approach to Computerized Processing of Uncertainty, Plenum Ed, New York, (1987).

[3] Dunn E. G., Keller J. M., Marks L.A., Ikerd J. E., Gader P.D. and Gosey L.D., "Extending the application of fuzzy sets to the problem of agricultural sustainability", Proceedings of the 3rd International Symposium on Uncertainty Modelling and Analysis (ISUMA '95), IEEE Computer Society Washington DC, USA, 497-502, (1995).

[4] Klir G. J. and Yuan B., Fuzzy sets and fuzzy logic. Theory and applications, Prentice Hall PTR, Upple Saddle River, New Jersey, (1995).

[5] Henn V., "Fuzzy route choices model for traffic assignment", Fuzzy Sets and Systems, 116: 77-101, (2000).

[6] Latouche S., Come sopravvivere allo sviluppo. Dalla decolonizzazione dell'immaginario economico alla costruzione di una società alternativa, Ed. Bollati Boringhieri, Torino, (2005).

[7] Litman T., Well measured. Developing indicators of comprehensive and sustainable transport planning, Victoria Transport Policy Institute, (2008).

[8] Mamdani E. H., "Application of fuzzy logic to approximate reasoning using linguistic synthesis", IEEE Transactions on computers, 26(12): 11821191, (1977).

[9] Organization of Economic Cooperation and Development (OECD), "Towards sustainable transportation", Oecd Proceedings of the Vancouver Conference, Oecd, (1996).

[10] Rassafi A. A. and Vaziri M., "Sustainable transport indicators: definition and integration", International Journal of Environmental Science and Technology, 2(1): 83-96, (2005). 
[11] Rossi R., Vescovi R. and Gastaldi M., "An application of fuzzy sets and possibility theory to the goods transportation choices of manufacturing companies", 22nd European Conference on Operational Research Stream: Transportation and Logistics - Invited session, Prague July 8-11, 2007.

[12] Rossi R., Vescovi R. and Gastaldi M., "Analisi dei risultati di un'indagine "SP" sulle scelte di trasporto merci delle aziende di produzione basata sulla teoria degli insiemi fuzzy", Interporti, scali merci, centri logistici e sviluppo competitivo. Venezia, 17 Nov 2005, Aracne Ed., Roma, 29-44, (2006).

[13] TRB, "Toward a sustainable future; addressing the long-term effects of motor vehicle transportation on climate and ecology", TRB Special Report 251, National Academy Press, (1997).

[14] Yannis A. P. and Andriantiatsaholiniauna L. A., "Sustainability: an illdefined concept and its assessment using fuzzy logic", Ecological Economics, 37: 435-456, (2001).

[15] Zammuner V. L., I focus group, ed. Il Mulino, Bologna, (2003).

[16] World Commission on Environment and Development (Wced), Our Common Future, Oxford University Press, Oxford, (1987). 